\title{
Snitch. Snake. Mole. Books.: Examining Responses to "Insiderl Outsider" Researchers in Corrections
}

\section{TaLisa J. Carter ${ }^{\mathrm{a}}$ and Chelsea Thomson ${ }^{\mathrm{b}}$}

${ }^{a}$ American University, Washington, DC, USA; ${ }^{b}$ National Association of Counties, Washington, DC, USA

\begin{abstract}
Qualitative researchers face unique challenges when conducting original data collection within facilities of confinement. These challenges are shaped by a range of factors including the study's research design, researcher identity, and organizational climate of the facility. Although the barriers of data collection in corrections are known, literature providing context, nuance, and recommendations for overcoming these obstacles is sparse, especially for qualitative fieldwork. This work addresses this gap by examining responses of correctional employees to observational research. During data collection, correctional staff called the primary author "snitch," "snake," "mole," and "Books." This paper investigates these labels and offers suggestions on how future researchers can navigate their experiences.
\end{abstract}

JQCJC "Qualitative Criminology," (2022)

Vol. 11, Iss. 2, 142-165

ARTICLE HISTORY

Received 8/28/2021

Accepted 10/25/2021

\section{KEYWORDS}

Insider, corrections

research, correctional staff

Conducting research in prison poses challenges such as navigating institutional restrictions, gaining access, juggling stakeholders with conflicting interests, building rapport with those detained and working in carceral facilities, and establishing relationships with the corrections community that will translate to data collection informed by experience rather than assumptions. The obstacles that prison researchers face can be downright daunting for many. Researchers who have experienced the carceral environment, whether via employment or incarceration, are uniquely positioned to overcome these obstacles. In fact, an increasing number of formerly and currently incarcerated people and correctional staff are taking roles in academia and conducting research, offering an insider perspective to improve scholarship and institutions (Tietjen, 2019; Ross et al., 2015; Jones et al., 2009). To be clear, we are not arguing that those who have lived or worked in corrections are better researchers than their counterparts. Instead, this article focuses on how researchers with these experiences offer a unique perspective; therefore, their distinctive status is worthy of study. 
"Qualitative Criminology"

Convict Criminology is an exemplar of advancing research through insight gleaned from prison experience. The group consists largely of students, academics, researchers, practitioners, and other professionals who are formerly incarcerated; this "new" criminology also embraces "non-cons" (those never incarcerated) that share their goals (Tietjen, 2019). The experiences, perspectives, and scholarship of those impacted by the system are critical to the advancement of corrections, Criminology, and Criminal Justice. This is also true of those who have worked in confinement facilities, though the narrative around scholarship by former correctional officers is entirely different. Work by former correctional officers turned scholars does not face the same level of scrutiny, stigmatization, and/or skepticism levied against Convict Criminology; but it should. Experiencing corrections-regardless of uniform—can greatly impact perspectives and in turn, approaches to research and scholarship. Regardless, discussions that highlight the vast complexities, challenges, and limitations of conducting research in prison/jail as a former corrections employee are uncommon in the literature.

This gap exists for several reasons including the power and privilege associated with being both a correctional officer and an academic. First: power. Individuals who are former correctional officers turned academics have worked in positions of power, capable of making decisions that impact others in significant ways. Correctional officers have the authority to grant/remove the privileges of incarcerated people including commissary and visitation. In doing so, officers alter the experiences of people who are detained. Similarly, academics are often considered sources of knowledge. They determine assignments, grading criteria, and degrees of leniency granted to students taking their courses, thereby shaping their classroom experiences and grading outcomes. Second, privilege. Privilege is defined as "a special right, advantage, or immunity granted or available only to a particular person or group" (Oxford, 2021). As members of law enforcement, correctional officers are granted certain privileges including a wide range of discretion, the protection, rights, wages, and benefits through union representation, and job security (Haggerty \& Bucerius, 2021; Liebling, 2000; McCoy, 2017). Similarly, academics receive privileges attached to their educational achievements such as social prestige, continued employment through tenure, employment benefits, academic freedom, the opportunity to pursue their intellectual interests, and access to "perks" such as reduced parking costs, dining privileges, and the ability to take advantage of campus amenities (Cardoso et al., 2018; Clarke et al., 2012). And finally, former correctional officers turned scholars have not primarily relied on ethnographic and other qualitative methodological approaches to research, in turn, they often do not disclose their ex-officer status in scholarship. Considering power, privilege, and nondisclosure, the lack of scholarly interrogation of prison research conducted by former correctional officers makes sense. We take the perspective that research by former correctional officers faces similar challenges and privileges to those seen in Convict Criminology. In short, merging experiential and 
academic knowledge provides valuable insight that can advance the field in meaningful ways. As such, it is critical to engage in discussions that highlight the challenges of navigating these dual statuses: former correctional officer and researcher.

Access to prisons, starting with IRB approval, through negotiations and relationships with stakeholders, and ongoing trust throughout the research process, is difficult to obtain (Patenaude, 2004). Researchers must work with correctional administrators, the gate keepers who often prioritize agency benefits over academic research, to secure access and negotiate the topics of interest throughout the research period (Patenaude, 2004). Although the benefits of a strong relationship between researchers and corrections institutions are evident and abundant, these relationships are not forged easily. As a control-oriented organization, prison facility administrators are risk averse and skeptical of outsiders, especially researchers (Reiter, 2014). In addition to the logistical hurdles, researchers also face challenges when interviewing people and may be labelled as "informants" which is "synonymous with informer, snitch, or rat and carries negative, often life-threatening, consequences" (Patenaude, 2004, p. 74S). As an outsider, researchers' participation in certain tasks is limited and their ability to observe true behaviors is restricted; participants are aware they are being observed (Castellano, 2007). While previous research experience with a specific institution or stakeholders aides a researcher in overcoming these hurdles, the experience ushers in other complications, especially for ethnographic studies. Challenges include bias, value judgement, and the appearance of "taking sides," even if the assumption is untrue (Becker, 1967; Liebling, 2001). In short, researchers who were previously employed as correctional officers are not immune from the complexities inherent in corrections research.

This paper examines how the first author, a former correctional officer turned academic, navigated the challenges of being both an insider and an outsider while conducting observational research in a Mid-Atlantic Department of Correction. We first review literature on Insider/Outsider roles in research. Then, we analyze the labels given to the researcher in the field-snitch, snake, mole, Book-through the Insider/Outsider framework using fieldnote data. The paper concludes by suggesting a series of implications for future research, specifically those conducted by scholars with prior experience in corrections. 
"Qualitative Criminology"

\section{Literature Review}

\section{Defining and Understanding Insider and Outsider Roles}

At face value, the definitions of outsider and insider are straightforward whereby the former is "a person who does not belong to a particular group" and the latter is "a person recognized or accepted as a member of a group, category, or organization" (MerriamWebster, 2021). As an insider, an individual has a unique experience and understanding that is shared among a certain population, reducing some of the space between individuals. The ability to identify and assimilate with a group provides a baseline understanding between a researcher and participant (Dwyer \& Buckle, 2009). An outsider is perceived as an individual lacking the experience to understand a group's characteristics and therefore cannot comprehend certain actions or decisions, introducing stigma against a certain population. However, these roles are difficult to define and understand in practice, even more so in a prison setting as there are several groups within the facility, each with their own characteristics and norms. Researchers in the prison setting - contend with these two groups, their role in each, and how to move between the two.

While an insider role can provide a level of access to and acceptance among a population, an official researcher role can counteract this status (Dwyer \& Buckle, 2009; Kanuha, 2000). The actions taken, language used, and decisions made by a researcher in a prison can further distance or entrench their status in either group, negatively or positively. The implications of these roles are like a double-edged sword as the dual statuses can distance some groups at the expense of others while research acknowledging and embracing this status can be questioned:

For each of the ways that being an insider researcher enhances the depth and breadth of understanding a population that may not be accessible to a nonnative scientist, questions about objectivity, reflexivity, and authenticity of a research project are raised because perhaps one knows too much or is too close to the project and may be too similar to those being studied. (Kanuha, 2000, p. 444)

To address the critique of research as lacking objectivity, researchers are encouraged to engage in self-reflection, evolving the notion of an Insider/Outsider role (Kanuha, 2000; Drake \& Harvey, 2014). Reflexive work and introspection are beneficial "to acknowledge researchers as active participants whose identities and biographies influence and inform their understandings of their research" (Jewkes, 2012, p. 69). Furthermore, as every researcher operates within a unique set of characteristics, it is important to understand how that perspective interacts within the research setting (Dwyer 
\& Buckle, 2009). As all researchers are "insiders of many systems," this inside knowledge should not be disqualified but researchers should instead engage in "reflexive awareness" by leveraging their knowledge of a community to better understand their research (Brannick \& Coghlan, 2007, p. 60; Jewkes, 2012).

Practitioners, or people with lived experience, turned researchers lie within the "hyphen of insider-outsider" (Kanuha, 2000, p. 443) or an "inbetweener" who can navigate fluidly between the two ends of the spectrum (Milligan, 2016). Those with experience as correctional officers have an insider status that bears a level of legitimacy, acceptance, and trust not readily available to researchers as outsiders. However, this insider status conflicts with a researchers' outsider status that is associated with stigma, skepticism, and the inability to truly understand the group. Those who lie within this gap can take actions that either push them towards one end or the other of the Insider/Outsider continuum.

\section{Insider/Outsider Intersection: Researcher and Correctional Officer}

Researchers in prison settings must confront the assumptions and labels people in the correctional system place on them. As outsiders, people in the correctional setting try to "fill in the blanks" with labels and generate meaning to place the researcher in a role, subsequently impacting the researcher's relationship with those in the institution (Rowe, 2014; Jewkes, 2012). Researchers face stigmas during their work; for instance, some may need to defend themselves from accusations of siding with the people who are incarcerated rather than correctional officers (Beyens et. al., 2015). While building rapport is key, the "prison officer culture, which insists that there are hidden meanings in everything that happens in a prison," (Beyens et. al., 2015, p. 70) makes it difficult for researchers to shirk and disprove the assumptions.

Correctional officers must also attend to the assumptions and stereotypes that those outside of the corrections field place on them and how those assumptions subsequently impact their identity. Correctional officers are stigmatized as "professional babysitters" and "the scum of law enforcement" (Tracy \& Scott, 2006, p. 7). Jacobs and Retsky characterize the prison guard role as "polluted" and "sadistic, corrupt, stupid, and incompetent" (1975, p. 10). Administrators at times infer that those who become correctional officers accept these positions when they lack other vocational opportunities, will stay until they find a more attractive position, and are often unable to adjust to the job demands (Jacobs \& Grear, 1977). The media often depicts correctional officers negatively in news stories: sensationalizing the violence officers face from those incarcerated, highlighting those who engage in job-related misconduct, or reporting on those who commit crimes unrelated to the job (Vickovic et al., 2013). These news cycles in turn can 
"Qualitative Criminology"

generate negative stereotypes of correctional officers as "morally tainted" because of their work with those incarcerated, labeling them as public servants not worthy of the heroism often placed on firefighters or EMTs (Vickovic et al., 2013). However, the media's portrayal of correctional officers may not align with the public who see correctional officers' role as meaningful, useful to society, and an opportunity to help others (Sundt, 2009). These assumptions do not always align with the normative code among correctional officers. This code primarily reflects solidarity among co-workers, concerns about being manipulated by those who are incarcerated, and intolerance for squealing or gossiping (Farkas, 2012).

With correctional officers' norm of solidarity and a disdain for snitching coupled with a researchers' identity as an outsider who prison staff may not trust, it is difficult to combine these two roles without being labeled a snitch, informer, or other stigmatizing term. The perspectives and loyalties of each role impacts how an individual understands and accounts for the tensions and behaviors in prison (Liebling, 2001). To address this intersection and balance, Patenaude stresses the importance of building rapport and being cognizant that the former correctional officer status could increase their legitimacy with other correctional staff but harm it with people who are incarcerated, similar to a "double-edged sword" (2004, p. 77S). While Patenaude developed trust with correctional staff easily through common jargon and experience, it was difficult to establish the same relationship with people who were incarcerated; Patenaude had to continually demonstrate independence, specifically through small actions, to build and maintain rapport with this group (2004). Correctional officers turned researchers should demonstrate a "genuine interest in the topic and people studied" while maintaining a neutral and unbiased perspective to maintain trust and rebuke the assumptions and stereotypes assigned to these roles (Patenaude, 2004, p. 80S). Marquart, filling the role as guard for research purposes, faced similar challenges and furthermore had to continually disprove rumors of being a spy (1986). Unlike Patenaude, Marquart had to prove himself as a legitimate guard through a critical incident rather than the minor actions that contributed to Patenaude's rapport among people who were incarcerated (Marquart, 1986). Both secured trust through keeping conversations and interviews off the record or confidential. This intersection provides challenges but, through building mutual respect and trust, individuals in these intersectional roles can achieve a unique perspective and insight.

\section{Contribution}

This work adds to an extremely small body of literature that addresses how correctional officers can effectively serve as researchers in confinement facilities as they navigate a complex Insider/Outsider status. Prior literature demonstrates that although former 
correctional officers may benefit from certain advantages when conducting research, they also face challenges that require them to act and adapt to establish and maintain rapport with research participants (Patenaude, 2004). Holding both an insider and outsider status, correctional officers turned researchers are both capable of building trust and wielding institutional knowledge to their advantage but also at risk of being labeled an informant and/or untrustworthy. Research that delves into the nature, consequences, and potential solutions to this dual Insider/Outsider status is underexplored in corrections research. This study seeks to fill this gap. Specifically, we rely on fieldnotes from observational research in a Mid-Atlantic Department of Correction to explore the following research question: How does Insider/Outsider status impact correctional employee perceptions of researchers?

\section{Data and Methods}

This study analyzes fieldnote data from a larger, mixed-method study focused on how correctional institutions respond to employee behavior using quantitative and qualitative data from training observations, human resources files, and electronic databases. The parent study was conducted at a Mid-Atlantic Department of Correction (MADOC) in the summer of 2017, during a time of high attrition and tension within the organization after an officer died on duty. These circumstances influenced the parent study as a renewed emphasis was placed on recruitment, training, retention, and morale during the time of data collection. The current project exclusively examines fieldnotes and observer memos from the first author who conducted the parent study, hereafter "observer." These notes detail interactions between the observer and study participants. Participants included both correctional cadets in training, officers, and staff.

Fieldnotes drawn from over 150 hours of observations of the training for correctional employees occurred over a 3-month period. Cadets are trained in MADOC's headquarters, a centralized location that housed offices of executives, human resources, the training unit, and other key administrative departments. During this time, the observer surveilled over 100 correctional cadets, officers, instructors, and staff members in 5 training classes. Three of the classes observed were training courses for new corrections employees. The remaining classes observed were refresher courses, required sessions to keep employees updated on policies and procedures in the field. Typically, each observed class had around 20 individuals. The demographic makeup of observed classes was consistently mostly white and male. Most observations were of one cohort of correctional recruits. This class graduated with 18 cadets and had an instructional team of 4 assigned correctional employees. It is important to note that the training center was

understaffed during the observational period. Fewer staff allowed the observer frequent 
"Qualitative Criminology"

opportunities to witness and engage with instructional staff, cadets, and other corrections employees, noting similarities and differences in style, approach, and interactions.

Considering our study's scope, we now focus on the interactions between the observer and the project participants. Scholarship notes observation research can range from being a complete observer (non-engagement with participant), observer as participant (engagement with participants during less active moments), participant as observer (engagement with participants during active moments), to complete participant (full engagement with participants) (Roller \& Lavrakas, 2015). The agreement between MADOC and the observer for this study required her to shift from being a complete observer to an observer as participant, depending on the context. The MADOC allowed the observation of training classes with two stipulations. The observer must: (1) maintain the confidentiality of all individuals observed and (2) provide constructive feedback to the instructional team upon request. Anonymity was maintained through two sets of pseudonyms for correctional cadets, staff, and instructors, a set that participants knew and an additional set they did not. When requested, the observer provided instructors with informal feedback regarding their approaches to teaching. Observer recommendations included cold calling on "quiet" cadets rather than letting a few voices dominate classroom discussion and being cognizant of the role of gender in the classroom.

The identity and purpose of the observer was made clear to corrections employees and cadets primarily through introductions from instructional staff or the observer. However, introductions were not always conducted at the beginning of the observation period, influencing how staff perceived the observer and the research project. Although observations were mostly non-participatory, at times, the observer shared her former experiences as a correctional officer alongside instructional staff to help make points clear. The instructional staff initiated these moments of participatory engagement as they were aware of the observer's previous corrections professional experience. For example, when discussing potential inmate manipulation techniques, she shared a story on the importance of being fair when selecting an incarcerated person to serve as a helper with various tasks to avoid potential manipulation and accusations of favoritism. We pause here to note our decision to use the word "inmate" to refer to incarcerated persons as this is the word used by correctional officers under observation. We understand that personfirst language acknowledges the humanity of those incarcerated, rather than stigmatizing language. Simultaneously, we recognized the importance of preserving the language of those observed when conducting observational work. When the class participated in partner activities, she served as a stand-in cadet if attendance was uneven that day. Additionally, the observer was given a cadet uniform to minimize her outsider status to observe shadow training which occurred within prison. 
The dual status of the observer is evident through the formal interactions (introductions, opportunities, and expectations) embedded in the research process. The approval of the research project was conditioned on sharing expertise as an academic (outsider) while she was simultaneously asked to share her professional experiences as a former insider. These interactions with correctional cadets, employees, and administrators throughout the entire research process provoked consistent reflexivity from the observer. While perceptions of the observer were not the focus of the parent study, it quickly emerged as critical during interactions with correctional staff. Each interaction, request, and even moments where the observer was "invisible" or "ignored" became noteworthy. In short, the observer's awareness of her positionality and the impact of her presence and actions on the research became key in the data collection process. As an additional reflexive note, this heightened sense of awareness also created times of awkwardness and discomfort that required consultations with outside researchers and a reliance of previous scholarship for guidance on navigating requests to be involved in MADOC events, collecting rich observational data, and remaining a researcher of ethics and integrity.

Noting the complexity of having this dual identity while conducting corrections research, we analyze fieldnotes and memos using NVivo, a qualitative software, to examine how Insider/Outsider status operates for corrections researchers. We utilized Tracy's phronetic iterative approach to analyze the data which allows for both emergent themes from qualitative data to emerge and the integration, referencing, and reliance on existing theory and guiding research questions in an alternating method until refined findings materialize (2019). We coded data in two cycles. The primary cycle led to the creation of 40 codes that were descriptive in nature and focused on the reception, interactions, and perceptions of the observer by the participants. The second cycle concentrated on how staff perceptions of the observer challenged the research process within correctional institutions. The second author coded the data first, and the first author followed. We chose this order intentionally as the first author is also the observer, created the fieldnotes, and experienced the interactions first-hand. While this familiarity with the data can be beneficial, by allowing the second author to lead on coding, we used intercoder reliability, collaborating on data analysis to enhance the credibility of findings (Tracy, 2019).

Seeking to answer the question, how does Insider/Outsider status impact correctional employee perceptions of researchers?, we report findings in four thematic sections that align with labels participants gave the observer during the data collection period: snitch, snake, mole, and "Books." We use pseudonyms to protect participants. 
"Qualitative Criminology"

\section{Findings}

It was early in the project, but it seemed like luck was in the observer's favor. She showed up for observations on day one, excited about the opportunity to go back to correctional officer training. She remembered what it felt like to show up for her first day of correctional officer training years ago: nerve-wrecking, empowering, intimidating, and overwhelming. And then it was over. Day 1 had gone well. Better than she expected. The cadets even asked her to participate in their potluck. She didn't hesitate. She made banana pudding - a quick and tasty solution to a lastminute invitation that could help build rapport. When she showed up with the bowl, the instructional team laughed and called her a sucker for being dragged into the cadet potluck. She shrugged and pushed forward, ready to engage with the cadets on an informal level. She, however, was not prepared for their casual chatter. The youngest among them, Derwin (Black/Male), added: "I didn't think she was a snitch, I thought she was a snake because snitches talk, snakes just record."

After the observer began data collection, training cadets openly discussed her presence, purpose, and their opinions about being a part of the study. Now familiar with the research, cadets started to include the observer in informal exchanges, a signal of acceptance as an insider. The content of these discussions, as demonstrated by this quote, served as a constant reminder of her outsider status as cadets openly laughed and debated on whether she was a snitch or a snake. Here, we use the quoted definition of the terms snitch and snake to aid in our understanding of the complex reception of former officers in corrections research that is guided by the Insider/Outsider framework.

Snitch

A snitch talks.

The primary role of the observer was inherently contradictory to snitching (i.e. talking). Observational data collection calls for researchers to record what they see, hear, touch, taste, and/or feel when experiencing a social phenomenon of interest. As mentioned above, observer introductions varied. Sometimes the observer had the opportunity to introduce herself to staff as soon as she met them. Other times, a gatekeeper (an instructional staff person, administrator, or other staff person familiar with the research project) made the introduction. Gatekeepers are individuals who have the authority to grant access and the social capital to vouch for the research and researcher as credible to other persons that are the focus of the study (Tracy, 2019). When gatekeepers made the introduction, the observer was intentional about recording how her presence and work were framed in fieldnotes. 
Hoping to show due respect to the correctional hierarchy, the observer allowed instructional staff to take the lead with introductions. Staff often assumed she was an intern and introduced her as such. When corrected, they were surprised because they typically interacted with college interns.

Oftentimes, circumstances delayed the introduction. For instance, the first time the observer interacted with one training class was on their "spray day," the day that cadets are pepper sprayed. Understandably, managing the teary eyed, anxious, and agitated cadets took priority over introducing the observer to the class. In other words, the nature of conducting research in corrections requires researchers to adapt to the context. These adaptations can directly influence how participants perceive researchers in the corrections space. Beyond limiting the observer's voice, diverse, and delayed introductions led to participants questioning the researcher's identity throughout the data collection process.

She decided to wear business casual to observe training classes. It seemed appropriate. It was work. So, the cadets initially assumed she was a counselor since she did not wear a uniform.

Although the observer addressed these minor mix ups with minimal effort, they reflect the larger pattern of participants tendency to make sense of the observer's presence according to the social cues of the correctional context and "fill in the blanks" by ascribing a role based on assumptions (Rowe, 2014). In other words, if not given any information, currently employed correctional staff labeled the observer an insider of sorts (a counselor rather than an officer) according to previous interactions with others inside the correctional context. Curious glances from cadets, officers, instructors, staff, and administrators were common. Whispers about the observer's identity often echoed through the corrections community until someone confronted her directly. This was precisely how Corporal Jackson (Black/Female) became an invaluable resource for the project.

She was the only Black woman on the instructional team. And she was striking. Her demeanor serious, uniform squared away, crisp lines, a natural afro crowning her no-nonsense expressions. And on the morning of the second day, it came as no surprise that she found a seat next to the observer and asked directly: "Why are you here?" After an in-depth conversation on the research project and professional experience, it became clear that Corporal Jackson was willing to be more than a project participant. She was a gatekeeper. 
"Qualitative Criminology"

This interaction with Cpl. Jackson was one of many the observer had with correctional instructors, staff, and administrators. The content of these chats varied, ranging from brief introductions to in-depth debriefs. Therefore, although the primary role of the observer was to silently squire happenings in training, her identity as both a researcher and former correctional officer made room for conversation and information exchange. At times, correctional staff tried to convince the observer to snitch in their best interest.

A native New Yorker, Rudolph is a respected correctional instructor with over 20 years of experience. A Black male whose rate of speech, energy, and enthusiasm "exhausted" his colleagues, it was common for Rudolph to have informal chats with the observer. Moving beyond the purpose of the research project, these talks mirrored an elder sharing wisdom with a young whippersnapper. He advocated for the researcher to address the weaknesses of the training program by making specific recommendations including providing more resources, updated instructional materials, and mechanisms to provide more support for the instructional team. Rudolph's passion for improving correctional training went beyond making suggestions for the research project, during the data collection period he was developing more comprehensive training handbook that things the current one lacked (e.g., appropriate attire).

Similarly, the observer engaged in other conversations meant to improve training as required in the memorandum of understanding created by MADOC. As discussed previously, the observer recommended strategies to instructional staff that would bolster classroom engagement and outcomes. These recommendations often occurred verbally and at the request of the instructors, who were mostly white males. Considering the observer created fieldnotes of occurrences both inside and outside the purview of the instructors, it is possible that these recommendations were indirectly snitching. That is, the Insider/Outsider status of the observer allowed her to witness events that the instructors did not. Therefore, exchanging information with the instructors may be considering snitching on the cadets, although this was a critical part of gaining access to MADOC.

In short, Derwin neither right nor wrong. Complete observers are not snitches; they don't talk. However, the research process is never that simple, especially for those who are navigating a dual identity. The Insider/Outsider status of the observer led to opportunities to snitch, perhaps to the advantage and disadvantage of the participants depending on context. Eventually, all correctional researchers somewhat "snitch" by disseminating research findings to an audience outside of the corrections community. 
Snake

A snake records.

On the other hand, these names also highlight the observer's outsider status. There is clear evidence (e.g., this very article) that Derwin was right; the observer was a snake who recorded the behavior, conversations, and other training events in books. Being considered a snake is not a compliment. In fact, Merriam-Webster's definition considers a snake "a worthless or treacherous fellow" (2021). Cadets considering the observer to be a snake directly implies their awareness of being watched and recorded. Social science labels the phenomena of participant behavior changing-subconsciously or consciously_from the research process as reactivity (Lewis-Beck, Bryman, and Liao, 2004). Therefore, although nicknames suggest familiarity, the category snake represents an outsider status that could lead to disingenuous behavior. Although this limitation is common in fieldwork and other forms of original data collection, corrections scholars with Insider/Outsider statuses face unique conditions that further complicate their work.

As discussed earlier, former correctional officers turned researchers may rely on their professional history to build rapport with the corrections community they are studying. This can be done in a myriad of ways including using corrections jargon, institutional knowledge, and networking with gatekeepers. When conducting observational research, corrections researchers must build trust but also collect data in ways that do not distract and/or interfere with the environment of study. In corrections, this presents a challenge as the environment demands flexibility, adaptability, and conformity to the rules and regulations of the institution. Creating positive relationships with subjects while taking fieldnotes (read: being a snake) in a corrections environment is a daunting task, even for observers with an Insider/Outsider status.

Part of correctional training is shadowing inside facilities. Cadets partnered with current officers to obtain hands-on-experience. The cadets prepared to shadow and so did the observer. On the first day, the prison prohibited her from bringing her notebook. She adapted. To create fieldnotes without a notebook, the observer recorded a debrief in her car after a 12-hour day in the field.

Here the rules of the prison posed a direct challenge to the research by initially preventing her from taking her notebook into the facility. While officers and other employees could bring items in, this difference reflects an outsider status. 
"Qualitative Criminology"

Realizing the inevitable loss of data and the inherent imprecision of relying on memory after such a long day, she reached out to several gatekeepers at MADOC for permission to bring a notebook in the facility. It worked.

The observer relied on the rapport built with gatekeepers to overcome these restrictions, a reflection of insider status.

Now equipped with a notebook, the observer again joined the cadets as they shadowed their more tenured colleagues in prison. However, she now realized that the prison environment prevented taking fieldnotes in a systematic way. Informal chats, security measures, available space, and other demands of the facility required full immersion. She adapted, again, jotting down key ideas, thoughts, descriptions, and events whenever she could.

The possession and use of the notebook became an issue that evolved as the observer navigated her Insider/Outsider status. The role of the observer (taking fieldnotes) conflicts with the demands of the prison environment. Again, while this is true for every corrections scholar, those with former professional experience may be even more sensitive to the carceral conditions based on their intimate knowledge of confinement facilities. Referring again to Derwin's quote, the observer was restricted in her snake-like activities (writing fieldnotes) as policies and conditions made it either impermissible or inappropriate, depending on the context. Noteworthy, analysis found the presence of the notebook contributes to what we describe as "research paranoia" among participants, enhancing the reactivity in their behavior and increasing their interrogations of the research. Ultimately, these traits resulted in the observer being called a mole. Next, we discuss the label mole and its implications on the reception of a researcher guided by the Insider/Outsider framework.

Mole

Shadowing came with more problems than a notebook. In business casual, she stood out. Standing out in prison is not a good thing. So, she was given a cadet uniform and told to stay close to the instructors as shadowing commenced. The uniform was a familiar fit although it lacked the badges that identified the others as active cadets. Throughout the day, she juggled taking fieldnotes and staying immersed in the busy prison environment. As the day ended, the Warden requested a chat with her. Too serious to be believably friendly, he asked: Are you a mole? 
Merriam Webster defines a mole as a spy who establishes cover; one who works in an organization and passes along information (2021). Taken together, it is clear why the observer was taken as a mole: she wore a uniform that was not hers, scribbled in a notebook whenever she could, and instead of being partnered with an active officer-she stayed close to the instructors. Alarmed at this abnormal behavior, the Warden initiated a conversation that directly confronts her purpose in the prison. After being accused of being a mole, the observer took the opportunity to explain the research. Regardless, being labeled a mole by the head of the prison demonstrates that correctional employees perceived the observer with suspicion. While any outsider within a prison community would provoke curiosity, the observer's attempts to blend in as an insider elevated her presence from questionable to skeptical. In other words, navigating an Insider/Outsider status caused corrections employees to distrust her.

These feelings of doubt manifested in employees demonstrating "research paranoia." We define research paranoia as the distrust participants show about how the research portrays them, their interests, the institutions they represent, etc. As mentioned in the snitch and snake sections above, the observer was transparent about the research project and openly took fieldnotes during the data collection period. Although the participants never directly asked the observer to share the content of the fieldnotes, they did express interest in the outcome of work and where it would be shared. Dylan, a white male cadet, asked if the observer was "writing good things about" him. Dylan's concern about the way he is portrayed in research was not uncommon among participants. In short, as a mole, the observer caused research paranoia due to the suspicion her presence and actions created among correctional employees. This can be a detriment to the research process. However, moles may also be able to establish a cover by creating an identity and connections that allow them to blend in. Therefore, "good" moles are excellent examples of individuals who successfully navigate having an Insider/Outsider status. The observer's actions mirrored that of the mole achieving inclusion-to a certain extent-but simultaneously faced instances of exclusion. Next, we discuss instances of inclusion and exclusion to further parallel an Insider/Outsider status with the mole label.

One month after observations began, it was time for the cadets to demonstrate their cumulative knowledge by participating in several hands-on tests, each requiring the cadet to use a different skill set as they alternated from one exam station to another. Initially, the observer watched and recorded events at each test station. Her focus landed on the locker room station where Cpl. Jackson and Rudolph created stress-provoking simulations that required the cadets to take control of the situation. Examples of the types of scenarios presented include detainees that were suicidal, non-compliant, or guilty of hiding a shank. The observer was told to stay to the side, out of the way. The cadets were told to ignore 
"Qualitative Criminology"

her presence and focus on the instructional staff only. As the day progressed and the scenarios continued, the instructional staff began to rely on the observer to aide in the simulations, slowly integrating her into the cast of characters that developed and enacted each scenario.

This example demonstrates how as an outsider, the observer, was excluded from the simulations. But because of her previous professional experience as a correctional officer, she held an Insider/Outsider status. This status allowed her to eventually be a resource to the instructional staff that could aid in creating and performing scenarios. Other instances of the observer being integrated and excluded based on having a dual Insider/Outsider status include being invited to ride to prison with the instructional team yet denied access to select team meetings; observing marching drills on the sidelines under a tree along the shade while also serving as a central location for breaks and informal chats; and having access to observe cadets shadowing in one prison yet denied access as they shakedown another. In all, the Warden's suspicions were right. Whether in uniform or not, the observer's function was as a snitch and a snake. Additionally, having insider knowledge while holding an outsider status made her a mole.

\section{Books}

By this time, she had observed cadets and instructional staff long enough to develop meaningful pseudonyms for each one. The inspiration for these monikers varied, including their physical appearance, performance on the physical training test, general demeanor, and parental status. Now integrated into the class and immersed in the research, she began using these pseudonyms aloud, instead of just on paper. The nicknames stuck. The cadets remembered them, answered to them, and understood their importance to the project. One afternoon out of nowhere, Michael (White/Male), asked a question: "Why don't you have a nickname?" The observer shrugged. It never occurred to her that she needed one. Besides, she wanted this work, and everything attached to it to carry her name. Dissatisfied with her response, Michael named the observer on-the-spot: Books. He said with confidence: "We'll call you Books." And it stuck.

A bit literal, the observer's given pseudonym "Books" integrates her as a part of the class community while simultaneously crystallizing her snake status. In short, the terms Books and snake reflect the complex nature of the observer's Insider/Outsider status. Daily, she quietly wrote in notebooks, sitting in the back of training classrooms. That is, of course, what observers do. What is critical for this study is how the observer was received by staff as she navigated her role as a researcher who is a former correctional officer. By granting her a pseudonym, the cadets demonstrated the familiarity 
of their relationship with the observer and their active participation in the project. To the current day, the participants still refer to the observer as "Books" symbolizing the strong rapport built during data collection, such enduring relationship suggests the achievement of insider status.

In contrast to the first three labels (snitch, snake, and mole), the nickname "Books" signals a positive research relationship in two ways: transparency and connection. First, participants giving the researcher the nickname "Books" signals transparency in the research process. In short, this label signals that correctional staff understood the researcher's presence. Second, being given a nickname signals connection beyond the formal researcher/participant relationship. The consistent presence of the researcher and occasional involvement in activities is reflected in granting her a nickname. While pseudonyms were a required part of the research process for anonymity, the researcher receiving one denotes a voluntary relationship. In fact, correctional staff continue to refer to the researcher as "Books," showing a connection beyond the project.

\section{Discussion}

In this study we utilized observation notes to examine perceptions of former correctional officers turned researchers as they navigate their Insider/Outsider status. Our findings demonstrate the complexity that inherently comes from having a dual identity, one of being professionally familiar with the inner workings of corrections while also tasked as a researcher (Kanuha, 2000). During data collection, the observer was labeled a snitch, snake, mole, and Books. These four titles, while striking, are symbolic of the way research participants perceived the observer. As defined by one correctional cadet, "snitches talk, snakes record." Talking and recording are vital components of a researcher's role, especially when conducting qualitative research. People perceive moles as untrustworthy individuals who enter spaces under false pretense to achieve alternative motives. Former correctional officers who engage in research can build rapport and blend in by relying on former professional knowledge and skills (Patenaude, 2004). This ability to camouflage makes those with Insider/Outsider statuses moles, as their presence can cause a level of distrust-even if they take a transparent approach. "Books" continues to be a term of endearment and connection between the researcher and participants although it was initially a literal nickname reflective of her work. The implications of being labeled a snitch, snake, mole, and Books by participants are profound for corrections researchers throughout each phase of the research process and can carry negative and positive implications (Patenaude, 2004).

Noteworthy, these four labels applied to the researcher by participants may not be purely distinct concepts. Instead, they may reflect a research paranoia scale that is 
"Qualitative Criminology"

reflective of the rapport and trust that exists between researcher and participant. Mole, for example, may represent one polar end of the spectrum where participants distrust the researcher and question their motives and the credibility of the research process. In contrast, "Books" is indicative of a research relationship consisting of trust, understanding, transparency, and respect. From the beginning of the research process, the Insider/Outsider status of the researcher shaped how individuals perceived her, which in turn influenced the project. The memorandum of understanding required the observer to rely on outsider knowledge to provide suggestions to training staff on how to improve their instruction. Simultaneously, when MADOC employees introduced the observer, they always mentioned her insider status-having prior correctional experience-to enforce the credibility, trust, and legitimacy of the researcher and the project. During data collection, the training unit included and excluded the observer from certain activities depending on the context and situation. When shadowing cadets inside facilities, wearing a uniform allowed the observer to blend in but also caused distrust, earning her the title mole. In this way, inclusion tactics led to exclusionary interactions. On the other hand, the observer was eventually welcome to join in on training activities as either a co-instructor or cadet, which was unremarkable. Here, after initial pushback (read exclusion), the observer experienced inclusion to the point of being commonplace. The complexities of an Insider/Outsider status show up at the end of the research project as well. Sound research protocol—a product of outsider status—demands participant anonymity, method transparency, and the hope of generalizability, even if slight. As our findings demonstrate, having prior correctional experience-insider status-facilitates strong relationships with research participants, similar to findings from other researchers (Patenaude, 2004). Building these relationships allowed participants to not only provide raw data through their interactions but they also weighed in on the final product of the research project. Specifically, participants expressed interest in reading the final work, ensuring the final product facilitates institutional change that represents employee concerns, and for the observer to represent individuals in positive ways. Ultimately, fluctuating between inclusion and exclusion further highlights the role that the Insider/Outsider duality played in the research.

\section{Implications}

Next, we discuss three implications for future research: acknowledging intersecting identities of researchers, rethinking key stakeholders in research projects, and the importance of intentionally committing to ubiquitous reflexivity throughout the research process.

First, individuals engaged in research should acknowledge the intersections of their identities, including their professional selves (Crenshaw, 1989; Jewkes, 2011; 
Brannick \& Coghlan, 2007). As everyone holds several identities and social positions across various systems, it is important for researchers to acknowledge these intersections within their work and the impact these identities play in the research process (Jewkes, 2011). Although it is instinctual to hold the title and obligations of a researcher in the forefront when engaging in research, individuals should acknowledge that the integration of professional experiences also plays a key role in the research process. In a society where professional identity can serve a large role in self-perception (Pietromonaco et al., 1987), it is odd that previous professional experiences are often ignored or obscured. We argue that individuals should value all their professional experiences and integrate them in their identity and efforts as a researcher. Future scholarship should continue investigating how real-world experience, specifically overlapping professional roles, shapes the research process.

Related, future research must also seriously reconsider the role of key stakeholders in the research process. Key stakeholders may often be selected by function and/or funding and are defined as individuals who can affect or are affected by the research process. For example, in a corrections research study the key stakeholders considered may be decision makers (administrators, politicians, and legislators), members of the correctional community (front-line officers, medical staff, and education staff), incarcerated persons (Carter, 2020), and individuals from the broader community. While each of these groups may be integrated in the research process in some way, the researchers themselves are often at the core of the process. It would be valuable for research teams to integrate individuals with both insider, outsider, or inbetweener status as members of the research team or at minimum key stakeholders that are central to the project, rather than periphery.

Lastly, we encourage researchers to commit to ubiquitous reflexivity throughout the research process. While this call for reflexivity may be a cornerstone for qualitative research, the complexities of corrections research and an Insider/Outsider status make it an appropriate suggestion for all researchers, regardless of methodology (Rowe, 2014; Jewkes, 2011; Beyens et al., 2015). As our findings demonstrate, having a sense of awareness of the impact that researcher presence and behavior has on participants and the overall project is critical at every phase. Beyond awareness, we emphasize the fact that the reception of researchers is a part of the research process. Sharing obstacles with building rapport, distrust, and receiving symbolic labels add to the credibility and validity of the project. It can also provide insight for researchers as they navigate future projects. Although exploring the labels snitch, snake, mole, and Books contributes to our understanding of how researchers can navigate the complexities of holding an Insider/Outsider status, we acknowledge limitations of the study. First, the researcher's awareness of the complex participant reactions to her presence grew as the study 
"Qualitative Criminology"

continued. Additionally, the parent study did not primarily focus on participant reactions to researcher presence. Therefore, fieldnotes do not consistently capture these exchanges. Future research should focus primarily on the reactivity of participants and how they perceive/interact with researchers. Additionally, only one researcher's fieldnotes are analyzed in this study. And this researcher was a young, Black female who held an Insider/Outsider status. Future work would do well to compare the reception of individuals who hold intersecting professional identities with those who do not, as well as contrast other identities and their impact on participant perceptions of researchers.

\section{Conclusion}

This research not only provides insight into the challenges researchers face when navigating projects in a corrections facility but more importantly explores the space between the Insider/Outsider roles. While an insider status, exemplified here by prior experience as a correctional officer, may convey legitimacy and trust, the first author's outsider status as an academic raised skepticism which led to correctional staff labeling her a snitch, snake, mole, and Books. Balancing these two roles reinforced the notion of a status in between insider and outsider, one that both hindered and enhanced the research process.

This research not only adds to the small existing literature in this space, but also highlights the importance, and to a larger extent the necessity, of bringing a researcher's whole self into the process. Leveraging both insider and outsider experience as well as the set of characteristics and perspectives everyone brings to their research project is critical to understanding the impacts one has in their project.

\section{References}

Becker, H. (1967). Whose Side Are We On? Social Problems, 14(3), 239-247.

Beyens, K., Kennes, P., Snacken, S., \& Tournel, H. (2015). The craft of doing qualitative research in prisons. International Journal for Crime, Justice and Social Democracy, 4(1), 66-78.

Brannick, T., \& Coghlan, D. (2007). In Defense of Being "Native": The Case for Insider Academic Research. Organizational Research Methods, 10(1), 59-74.

Cardoso, S., Carvalho, T., \& Videira, P. (2018). Is It Still Worth Working In Academia? The Views from Portuguese Academics. Higher Education Policy, 32(4), 663-679. 
Carter, T. (2020, June 16). COVID-19 in the Common Area: The Pandemic is Reinforcing the Interconnected Nature of Corrections. Urban Wire, Urban Institute. https://www.urban.org/urban-wire/covid-19-common-area-pandemic-reinforcinginterconnected-nature-corrections

Clarke, C., Knights, D., \& Jarvis, C. (2012). A Labour of Love? Academics in Business Schools. Scandinavian Journal of Management, 28(1), 5-15.

Crenshaw, K. (1989). Demarginalizing the intersection of race and sex: A black feminist critique of antidiscrimination doctrine, feminist theory and antiracist politics. u. Chi. Legal f., 139.

Drake, D., \& Harvey, J. (2014). Performing the role of ethnographer: processing and managing the emotional dimensions of prison research. International Journal of Social Research Methodology, 17(5), 489-501.

Dwyer, S., \& Buckle, J. (2009). The Space Between: On Being an Insider-Outsider in Qualitative Research. International Journal of Qualitative Methods, 8(1), 54-63.

Farkas, M. (1997). The Normative Code Among Correctional Officers: An Exploration of Components and Functions. Journal of Crime and Justice, 20(1), 23-36.

Haggerty, K., \& Bucerius, S. (2021). Picking battles: Correctional officers, rules, and discretion in prison. Criminology, 59(1), 137-157.

Jacobs, J. B., \& Grear, M. P. (1977). Drop Outs and Rejects: An Analysis of the Prison Guard's Revolving Door. Criminal Justice Review 2(2), 57-70.

Jacobs, J., \& Retsky, H. (1975). Prison Guard. Journal of Contemporary Ethnography, $4(1), 5-29$.

Jewkes, Y. (2012). Autoethnography and Emotion as Intellectual Resources: Doing Prison Research Differently. Qualitative Inquiry, 18(1), 63-75.

Jones, R. S., Ross, J. I., Richards, S., Murphy, D. S. (2009). The First Dime: A Decade of Convict Criminology. The Prison Journal 89(2), 151-171.

Kanuha, V. K. (2000). "Being" native versus "going native": Conducting social work research as an insider. Social Work, 45(5), 439-47. 
"Qualitative Criminology"

Lewis-Beck, M. S., Bryman, A., \& Liao, T. F. (2004). The Sage encyclopedia of social science research methods. Thousand Oaks, Calif: Sage.

Liebling, A. (2001). Whose Side are We on? Theory, Practice and Allegiances in Prisons Research. British Journal of Criminology, 41(3), 472-484.

Liebling, A. (2000). Prison Officers, Policing and the Use of Discretion. Theoretical Criminology, 4(3), 333-357.

Marquart, J. (1986). Doing research in prison: The strengths and weaknesses of full participation as a guard. Justice Quarterly, 3(1), 15-32.

McCoy, A. (2017). Prison Guard Unions and Mass Incarceration: Prospects for an Improbable Alliance. New Labor Forum, 26(1), 74-83.

Merriam-Webster. (n.d.). Snake. In Merriam-Webster.com dictionary. Retrieved March 18, 2021, from https://www.merriam-webster.com/dictionary/snake

Merriam-Webster. (n.d.). Insider. In Merriam-Webster.com dictionary. Retrieved March 18, 2021, from https://www.merriam-webster.com/dictionary/insider

Merriam-Webster. (n.d.). Mole. In Merriam-Webster.com dictionary. Retrieved March 18, 2021, from https://www.merriam-webster.com/dictionary/mole

Merriam-Webster. (n.d.). Outsider. In Merriam-Webster.com dictionary. Retrieved March 18, 2021, from https://www.merriam-webster.com/dictionary/outsider

Milligan, L. (2016). Insider-outsider-inbetweener? Researcher positioning, participative methods and cross-cultural educational research. Compare, 46(2), 235-250.

Oxford University Press. (2020). Privilege. Oxford English dictionary. Retrieved March 17, 2021, from https://www.lexico.com/en/definition/privilege

Patenaude, A. (2004). No Promises, But I'm Willing to Listen and Tell What I Hear: Conducting Qualitative Research among Prison Inmates and Staff. The Prison Journal, 84(4_suppl), 69S-91S.

Pietromonaco, P., Manis, J., \& Markus, H. (1987). The relationship of employment to selfperception and well-being in women: A cognitive analysis. Sex Roles, 17(7-8), 467-477. 
Roller, M., \& Lavrakas, P. (2015). Applied qualitative research design a total quality framework approach. The Guilford Press.

Ross, J., Zaldivar, M., \& Tewksbury, R. (2015). Breaking Out of Prison and into Print? Rationales and Strategies to Assist Educated Convicts Conduct Scholarly Research and Writing Behind Bars. Critical Criminology, 23(1), 73-83.

Rowe, A. (2014). Situating the Self in Prison Research: Power, Identity, and Epistemology. Qualitative Inquiry, 20(4), 404-416.

Sundt, J. (2009). Good Job or Dirty Work? Public Perceptions of Correctional Employment. Federal Probation, 73(3), 40-45.

Tietjen, G. (2019). Convict Criminology: Learning from the Past, Confronting the Present, Expanding for the Future. Critical Criminology, 27(1), 101-114.

Tracy, S. (2019). Qualitative research methods: collecting evidence, crafting analysis, communicating impact. Wiley-Blackwell.

Tracy, S., \& Scott, C. (2006). Sexuality, Masculinity, and Taint Management Among Firefighters and Correctional Officers: Getting Down and Dirty With "America's Heroes" and the "Scum of Law Enforcement." Management Communication Quarterly, 20(1), 638.

Vickovic, S., Griffin, M., \& Fradella, H. (2013). Depictions of correctional officers in newspaper media: an ethnographic content analysis. Criminal Justice Studies, 26(4), 455-477.

\section{Contributors}

TaLisa J. Carter, PhD, is an Assistant Professor in the Department of Justice, Law \& Criminology at American University, a non-resident fellow in Governance Studies at the Brookings Institute, an Affiliated Scholar at Urban Institute, and an Affiliate with the Center for Advancing Correctional Excellence! at George Mason University. Her research examines theoretical explanations of accountability in the criminal justice system, the role of identity in criminal justice professions, and the impact of colorism on criminal justice outcomes. Previously, she worked as a Deputy Corrections Officer in Savannah, GA where she supervised male and female residents with diverse classification statuses. Her work has been funded by the National Science Foundation and National Institutes of 
"Qualitative Criminology"

Health. Additionally, her work has been published in outlets including Race and Justice, Deviant Behavior, and Sociological Forum. ORCID: 0000-0002-1662-6089

Chelsea Thomson, MPP, is a Program Manager for Justice programs at the National Association of Counties. Her research interests include collateral consequences of incarceration, alternatives to incarceration, community investment, and holistic approaches to safety and justice. Previously, she worked at the Urban Institute's Justice Policy Center where her research focused on justice reinvestment and investments in community-based justice and public safety solutions. She holds an MPP from American University and a BA in political science from the University of Massachusetts Amherst.

\section{Acknowledgement}

The authors would like to acknowledge the Mid Atlantic Department of Correction and the study's participants for their part in the study. 